\title{
BRET sensors unravel that Plasmodium falciparum serpentine receptor 12 (PfSR12) increases surface expression of mammalian GPCRs in HEK293 cells
}

\author{
Pedro H. S. Pereira ${ }^{1,2}$, Gabriela Brito ${ }^{1}$ Miriam S. Moraes ${ }^{1}$, Camila L. Kiyan ${ }^{1}$, \\ Charlotte Avet $^{2}$, Michel Bouvier ${ }^{2^{*}}$ and Celia R. S. Garcia ${ }^{1^{*}}$

\footnotetext{
${ }^{1}$ Department of Clinical and Toxicological Analyses, University of São Paulo, São Paulo, Brazil

${ }^{2}$ Institute for research in immunology and cancer \& Department of Biochemistry and Molecular Medicine Université de Montréal, Canada.

${ }^{*}$ Co-corresponding authors
}

Correspondence should be addressed to:

Dr. Celia Garcia, Department of Clinical and Toxicological Analyses, School of Pharmaceutical Sciences, University of São Paulo, Av. Prof. Lineu Prestes, 580, São Paulo, SP 05508-900, Brazil. celiaregarcia@gmail.com

And

Dr. Michel Bouvier, Institut for Research in Immunology and Cancer, Université de Montréal, 2900 Boulevard Édouard-Montpetit, Montréal, Qc. H3T- 1J4, Canada michel.bouvier@umontreal.ca

\begin{abstract}
Malaria causes millions of deaths worldwide and is considered a huge public health problem for underdeveloped countries. The most severe cases of malaria present complications of the host circulatory system, which may cause clogging and rupture of blood vessels, leading to death or important sequelae. Because of the previously suggested role of thrombin and platelet aggregation in Plasmodium falciparum biology, we hypothesized that one of the GPCR-like proteins identified in the genome of the parasite, $P$. falciparum serpentine receptor 12 (PfSR12), could be a thrombin-activated GPCR. To test this hypothesis we used a series of Bioluminescence and Bioluminescence Resonance Energy Transfer (BRET)-based biosensors to investigate the signaling activity of PfSR12. Using an Obelin based biosensor, thrombin promoted a
\end{abstract}


PfSR12-dependent cytosolic $\mathrm{Ca}^{2+}$ rise in HEK293 cells. This $\mathrm{Ca}^{2+}$ mobilization was accompanied by DAG formation and PKC activation as detected using DAG and PKC BRET-based biosensors indicating a Gq/PLC/IP3 signaling pathway. The role of Gq was confirm using $\mathrm{G}_{\mathrm{q} / 11}$ knockout HEK293 cells as well as the Gq-selective inhibitor, YM254890. Further investigation revealed that PfSR12 is not itself a thrombin receptor but rather promotes the increase of cell surface expression of an endogenous thrombin receptor. This chaperone-like effect was not selective for thrombin receptors as PfSR12 expression also promoted an increased muscarinic type 3 receptor (M3R)-promoted DAG and PKC responses. This increase response was accompanied by an increase in surface expression of M3R. Our data indicate that PfSR12 acts as a chaperone and increases the expression of several GPCRs resulting in increased responsiveness to various hormones of mammalian cells that could contribute to the deleterious effects of Plasmodium falciparum infection.

\section{INTRODUCTION}

Malaria is a disease caused by Plasmodium genus protozoa, and P. falciparum species is responsible for the most serious human parasitic disease. It is estimated that 3.3 billion people live in areas at risk of infection by any species that causes the disease and during the year 2018, 228 million cases of the disease have been reported, leading to more than 405,000 deaths (World Health Organization 2019). Parasites resistant to drugs such as chloroquine and pyrimethamine/sulfadoxine already spread throughout the globe and the growing number of reports of parasites resistant to the latest generation of drugs such as artemisinin, atovaquone, and piperaquine is increasing especially in southeast asia, making it necessary to develop alternative strategies for the eradication of the disease (Amato et al. 2018; Ménard et al. 2018).

In recent years, it has been shown that the parasite has the ability to sense external molecules opening potential avenues for the development of therapeutics taking advantage of such signaling process. For instance, it has been reported that Plasmodium displays four G protein-coupled receptors-like (GPCR-like) proteins: PfSR1, PfSR10, PfSR12 and PfSR25 (Madeira et al. 2008). One of the ligands of these receptors, serpentine-like receptor PfSR25, has been recently identified as potassium. This potassium sensor is coupled to $\mathrm{Ca}^{2+}$ signaling in a PLC dependent pathway and modulates stress survival and antimalarial action in parasites (Moraes et al. 2017). Bioinformatic analysis of another of these proteins, PfSR12, predicts that it possesses a membrane targeting signal peptide, seven transmembrane domains and shows $30 \%$ homology with the human intimal thickness-related receptor (GPR180), associated with 
vascular restenosis (Tsukada et al. 2003). GPCRs add a new level of complexity to the Plasmodium-host interaction and give a new perspective on how signaling systems of these parasites may function.

G protein coupled receptors (GPCRs) are the largest family of proteins present in the human genome (Lander et al. 2001). GPCRs share a common structure, each consisting of a single polypeptide with seven hydrophobic transmembrane domains linked by three extracellular and three intracellular loops, an extracellular $\mathrm{N}$-terminus, an intracellular C-terminus. GPCR mediated signaling begins with the binding of an agonist on the extracellular surface of the receptor that transmits the signal to heterotrimeric $\mathrm{G}$ proteins (Rosenbaum et al. 2009; Kenakin 2013). While some G-protein coupled receptors are activated by small molecules, protease-activated receptors (PAR) are a class of membrane proteins that are irreversibly activated by protease activity (Houle and Hollenberg 2011). Among the 4 types of existing PAR, only PAR2 is not described as directly activated by thrombin, but they all have several proteases that may participate in the activation process (Adams et al. 2011).

The interaction of $P$. falciparum-infected red blood cells (iRBC) with endothelial cells generates a stimulus for the formation of the prothrombinase and factor Xase complexes by the endothelial cell, greatly increasing the concentration of thrombin and factor Xa in the iRBC microenvironment (Francischetti et al. 2007). In addition, iRBC can amplify the coagulation cascade independently of platelet aggregation in vivo if stimulated by TF (tissue factor) (Francischetti et al. 2008). Recently, in vivo trials in a controlled experiment showed a $17.7 \%$ increase in the endogenous thrombin generation in humans infected with $P$. falciparum, presenting a procoagulant state in the early stages of infection and indicating that the coagulation system reacts to infection and may play a role in the parasite lifecycle (Riedl et al. 2016). Another study revealed the interaction between $\mathrm{IRBC}$ and thrombin in brain microvascular endothelial cell disruption, showing that erythrocytes infected with late-stage parasites induce endothelial cell death and increase permeability due to the action of thrombin and delayed tissue recovery (Avril et al. 2019). Therefore, it is possible that iRBCs use the host's coagulation cascade to mediate cytoadhesion processes to the vascular endothelium to prevent spleen cleaning.

The evidence that $P$. falciparum parasites can use the coagulation cascade to their advantage during infection, along with the presence of a GPCR-like that is similar to GPR180, associated with vascular restenosis, led us to test the hypothesis that the PfSR12 acts as a sensor of the coagulation cascade components. Our results show that HEK293 cells can mobilize $\mathrm{Ca}^{2+}$ due to $\mathrm{PLC} / \mathrm{IP}_{3}$ pathway activation mediated by $\mathrm{Ga}_{\mathrm{q} / 11}$ family proteins when stimulated by thrombin. Further investigation revealed that PfSR12 is not itself a thrombin receptor but rather promotes the increase of cell surface 
expression of endogenous receptor acting as a chaperone-like protein promoting an increased responsiveness to the activation of different GPCRs including the PAR and the muscarinic receptors.

\section{METHODS}

\section{Cell culture}

Human Embryonic Kidney 293 SL (HEK293SL) cells were cultivated in flasks with Dulbecco's Modified Eagle Media (DMEM) supplemented with 10\% Fetal Bovine Serum (FBS) and 100 units $/ \mathrm{mL}$ penicillin and $100 \mu \mathrm{g} / \mathrm{mL}$ streptomycin. The flasks were kept at $37^{\circ} \mathrm{C} / 0.5 \% \mathrm{CO} 2$ incubator.

\section{Transfection}

HEK293SL cells were co-transfected with pCDNA3.1(-) plasmid containing the codon optimized version of PfSR12 (PF3D7_0422800) and plasmids containing components of the biosensor used. Transfection of cells were done using Branched Polyethylenimine (PEI, Millipore-Sigma) in a proportion of $3 \mu \mathrm{g}$ per $1 \mu \mathrm{g}$ of DNA directly in culture media. Cells were then kept for 48 hours at $37^{\circ} \mathrm{C}$ before luminescence or BRET experiments were performed.

\section{Constructs}

The codon optimized sequence of PfSR12 was synthetized by Genscript Corp. resulting in the following sequence:

ATGATTCGAAGAAAGTGGTCTAAGATCAAACTGGCTATTTATTTTATCGCATTCTAT TATTTGACTAAGATCGACGAAAAATGTTTGCTGATCAAGGAAGGAGAATTGAATCT GAGTATCACTAATGTGCACGATAACAACTATATGATTTCCGAAAAATATAATAAGTA CTACATACTGTCACTTCTCTATAAGTTTGGGGGCATCCTGAAAGAAATTTACGACA AGAAGATCTTCGTAAAAAACAAAAGCTGCAATAATTTCATGGTCAGTTCTAAAGTG ATCTATGGGCTTTATAACGACATGAACTATTCAAAATATTCTAATTTTTGTTTCTCTA AGAACGCCAACAATGGCGTTGTTATACTCAGCAACTTGTACGTCCCTAACACCAA GTTCCTGATCCTCGACAAGAGTGACGATGAGATTTATAACTATGGTAAGAACAAGA ATGGAAAGACATGCGAGGACTTGGAAAAGATTGCACTGTTTGTGCACCCATTGAA CGACATTCCTCCCGAGCTCATGAACAAGACATATTTCGTGTATCAAAAAGATATTG AGAAGTCTCTGACCGACAAAAAACTGAACTTTATCCTCTTGAACTGCGGAAACAAA ATTAAGAATGCCTTCAAGATTGAGTTCAAAAACAACATGAATTTCCTGAAAAACCAT TTTTCCTGTGAGGAACAGGGACTGTTTGAGATTCACATGCTGCTTATTGTGCTTCT GTTTGTCCTGAGTCTTGTTTACTATAGGAAAAGAAAAAATCTGAATAATACCAATAA CGTGCTGAAGGAGGCCATCCATTGTTCATACCTGTTCTTTCTGCTTTCTAATATTCT TTACTTTATCCATCTGATTAGTTACGCCTTCAACGGTTCTGGCTTCAGTATTTTGAA AGTGCTGTCCCAGATCTACGAAGCCATCTTTGATTGCTTCATTCTGGTGATCATTT ACTACATCTTCAACAATGATATGCAAAAAAAAAAAGAGGAGACGATTCGGGTGGC CTTCACCTATTCAATCCTGAAGTTTATCTACATCCTGTTCGAAATTCAGAATAATCA GGAACTGGACCTCTATAGCACCCTGCATTCCATCGTCGCCCTTCCCTTTGTGGTG TATCGCATCATAGTCGCAGTGCTCAATTATGATAATAGCAAAAAACTGCTTAAGGA AAAAACCCAGGTGGACGAAAAGTTCTACGTACTCTTCGACACCTTCTTCTATAATT 
TGTGGATACTCAGTATCCCTGTGCAGTACTTCCTGATGAAGTCCTTCAGTCTGCAC TTCACCCATCTGTTCGTTCACTTTTTTAACCTGTACATACTTATCTACCTGGTCTAC AATCTCTCCGAGGAGAAATTCGAAGTACTGGAGTCAAAACACCCCTACCTCGATC TGAACTGA

The codon optimized sequence was inserted in pcDNA3.1 plasmid for mammalian expression. For immunodetection experiments, addition of a N-terminal Hemagglutinin (HA) epitope was done using Q5 Site-Directed Mutagenesis Kit (New England Biolabs) following manufacturer recommendations.

\section{Calcium mobilization measurement}

Calcium mobilization measurements were performed transfecting HEK293 cells with a plasmid containing an Obelin biosensor. Obelin is an Aequorin analog that consists of a single $22 \mathrm{kDa}$ polypeptide chain with a high affinity for 2hydroperoxycoelenterazine. Obelin can consume its substrate to produce blue light spontaneously, but in the presence of free $\mathrm{Ca}^{2+}$, the intensity of the light emission is one million times higher (Illarionov et al. 2000; Gealageas et al. 2014). Cells were washed in PBS buffer (137 mM NaCl, 2,7 mM KCl, 4,3 mM Na $2 \mathrm{HPO}_{4}, 1,4 \mathrm{mM} \mathrm{NaH} \mathrm{PO}_{4}$, $\mathrm{pH}$ 7.4), incubated for 2 hours with $100 \mathrm{nM}$ Coelenterazine $\mathrm{Cp}$ and washed before initiating measurements using a spectrophotometer (SpectraMax M, Molecular Devices) equipped with injectors allowing the detection of luminescence in a kinetic mode.

\section{Bioluminescence Resonance Energy Transfer (BRET) assay}

Before reading, cells were washed in PBS buffer $(137 \mathrm{mM} \mathrm{NaCl}, 2,7 \mathrm{mM} \mathrm{KCl}$, 4,3 mM Na $2 \mathrm{HPO}_{4}, 1,4 \mathrm{mM} \mathrm{NaH} \mathrm{PO}_{4}, \mathrm{pH} 7.4$ ) and incubated 15 minutes with 100 $\mathrm{nM}$ bis-desoxi-coelenterazine (DeepBlue ${ }^{\mathrm{TM}}$ ) before initiating BRET measurements using a spectrophotometer (Mithras LB 940, Berthold Tech.) equipped with filters allowing the detection of luminescence at different wavelengths simultaneously. BRET values in the presence of different compounds were monitored in a kinetic mode. The time-dependent differences in BRET values were quantified and used as a readout for the activation of the pathways monitored (see the description of the biosensors used below). BRET values were determined by rationing the luminescence emitted at 510 $\mathrm{nM}$ (acceptor) over the luminescence emitted at $395 \mathrm{nM}$ (donor).

The DAG biosensor is a unimolecular BRET-based sensor used to detect the formation of diacylglycerol in the plasma membrane. It is composed of a protein chimera containing a domain that attaches the biosensor to the membrane through myristoylation/palmitoylation, a GFP (acceptor), a long flexible linker, RLuc (donor) and a DAG interaction domain c1b from PKCס (Figure 2A) (Namkung et al. 2018). 
The PKC biosensor is a construct of an RLuc conjugated to two PKC phosphorylation sites (TLKI and TLKD) linked by a flexible linker to phosphotreonine interaction domains (FHA1 and FHA2) and a GFP (Namkung et al. 2018) (Figure 4A).

The EPAC biosensor is an intramolecular BRET biosensor consisting of a modified EPAC containing an RLuc and a GFP in its structure (Breton et al. 2010). In the native state of EPAC, RLuc and GFP are close enough to generate a BRET signal. However, when a cAMP molecule is bound at the active site of the enzyme, it undergoes a conformational change that moves GFP and RLuc away from each other resulting in a decrease in BRET (Figure 6A).

\section{ELISA}

After transfection with HA-Tagged versions of the protein of interest, HEK293SL were washed with PBS once and fixed 3\% PFA in PBS for 10 minutes. After fixation, cells were washed extensively with wash buffer (BSA 0.5\% in PBS) and incubated in the same buffer for 10 minutes. Cells were then incubated with Anti-HA-HRP 1:2000 in wash buffer for one hour at room temperature, and 30 minutes with VibrantDye 1:1000 in wash buffer at room temperature. The fluorescence of DNA-bound VybrantDye was read in a spectrophotometer (Mithras LB 940; Berthold Tech.) using excitation 516nm / emission $563 \mathrm{~nm}$ and the HRP-generated luminescence read after 2 minutes incubation with enhanced luminol-based chemiluminescent (ECL, GE Healthcare) 1:1. Surface expression of GPCR was calculated by the ratio luminescence/fluorescence.

\section{RESULTS}

\section{PfSR12 induces $\mathrm{Ca}^{2+}$ release in HEK293SL cells with thrombin}

Preliminary experiments screening 16 ligands for their ability to promote calcium mobilization in HEK293T cells expressing PfSR12 revealed thrombin as the only compound that could promote an increase in cytosolic $\mathrm{Ca}^{2+}$ concentration. To further investigate whether PfSR12 could confer a selective thrombin response, HEK293SL cells expressing or not PfSR12 were treated with thrombin and the cytosolic calcium level assessed using an Obelin-based calcium sensor as described in the methods (Figure 1). The signal promoted by the calcium ionophore A23187 was used to standardize the cell number in each sample. PfSR12 transfected cells showed a larger increase in cytosolic calcium in comparison to cells transfected with an empty vector after thrombin treatment (Figure 1A) confirming that the expression of PfSR12 can confer a thrombin-mediated calcium response. The effect of thrombin was dependent on the amount of PfSR12 transfected (Figure 1C). 
Once observed that thrombin can elicit PfSR12 dependent cytosolic $\mathrm{Ca}^{2+}$ increase, we investigated the formation of other second messengers, G-protein interactions and desensitization/internalization dynamics. For this purpose, we used BRET based biosensors that can measure DAG formation, PKC activity, and CAMP accumulation.

\section{PfSR12 promotes DAG production in a $\mathbf{G}_{\mathrm{q} / 11}$ dependent manner}

Since the response observed after thrombin addition was an increase in calcium, an engagement of the $G_{q}$ signaling pathway was hypothesized. Since $G_{q}$ activation leads to the activation of PLC and the generation of DAG, the ability of PfSR12 to promote DAG production was assessed using a BRET-based biosensor to detect this molecule as described in the methods (Figure 2A).

When HEK293SL cells were co-transfected with PfSR12 and the DAG biosensor, thrombin promoted a significant increase in BRET signal corresponding to DAG formation (Figure $2 \mathrm{~B}$ and $\mathrm{F}$ ). The BRET increase was significantly higher in PfSR12 transfected cells when compared to cells expressing the $\mathrm{G}_{\mathrm{i} / \mathrm{o}}$ coupled type-2 Dopamine Receptor (D2R) (Figure 2B and 2C). The thrombin-promoted DAG response was marginal in D2R-transfected cells; the response most likely resulting from the background response evoked by the endogenously expressed thrombin receptor in HEK293 cells (HEK293 cells have been shown to express low levels of PAR1, PAR2 and PAR4 expression (Atwood et al. 2011). The D2R thus provided a good negative control confirming the selectivity of action of PfSR12 in promoting a thrombin-mediated DAG response. The DAG response was $\mathrm{G}_{\mathrm{q} / 11}$ dependent as it was almost completely abolished by treatment with the $G_{q / 11}$ family-selective protein inhibitor $Y M-254890$ (Takasaki et al. 2004) (Figure 2D and 2E).

To confirm the dependence of PfSR12-mediated signaling on $G_{q / 11}$ family proteins, knockout cells for this family of proteins were used with re-expression of each $G$ protein knocked out. The result was consistent with expectations: no DAG formation was observed in $G_{q / 11}$ knockout cell line (Figure $3 A-B$ ) but was restored when the cell was supplemented with $\mathrm{G}_{\mathrm{q}}$ (Figure $3 \mathrm{C}-\mathrm{D}$ ) or $\mathrm{G}_{11}$ (Figure $3 \mathrm{E}-\mathrm{F}$ ). The re-expressionof $\mathrm{G}_{\mathrm{q}}$ and $G_{11}$ caused a significantly greater DAG formation increase in in PfSR12 transfected cells when compared to D2R-transfected cells (Figure 3G); the marginal eincreas observed in D2R-transfected cells, most-likely relfecting again the activation endogenously expressed PARs in HEK293 cells. 


\section{PfSR12 induces PKC activation dependent of $\mathbf{G}_{\mathrm{q} / 11}$ proteins in HEK293SL cells}

To determine if a downstream effector of DAG production and calcium mobilization can be activated by PfSR12, the ability of thrombin to stimulate PKC in PfSR12-expressing HEK293 cells was assessed using a BRET-based PKC sensor (Namkung et al. 2018). As detailed in the methods, this construct consists of an active PKC substrate that changes conformation after threonine phosphorylation bringing GFP and RLuc in closer proximity leading to BRET. As expected, PKC activation is also higher in PfSR12 transfected cells compared to D2R transfected cells (Figure 4 B-D), and the signal is lost when cells are treated with YM-254890 (Figure 4 C-E). In addition, it is possible to observe the same dependence on $G_{q / 11}$ proteins family as seen for the DAG biosensor: the signal was lost in knockout cells for the $G_{q / 11}$ family (Figure 5 A-B) but restored when supplemented with, $\mathrm{G}_{\mathrm{q}}$ (Figure $7 \mathrm{C}-\mathrm{D}$ ) and $\mathrm{G}_{11}$ (Figure $5 \mathrm{E}-\mathrm{F}$ ).

\section{PfSR12 does not activate cAMP production}

Another common second messenger downstream of $\mathrm{G}$ protein activation is cyclic AMP (cAMP). To search for Gs and Gi PfSR12 coupled signaling, the EPAC biosensor was used as described in the methods. This biosensor is useful for measuring an increase in intracellular CAMP, a second messenger formed primarily by the $\mathrm{G}_{\mathrm{s}}$ family mediated signaling pathway. No activation of EPAC could be detected, which probably reflects the lack of interaction of PfSR12 with $\mathrm{G}_{\mathrm{s}}$ family proteins (Figure 6B). As a positive control, cells were transfected with V2R, which is known for the ability to activate the cAMP pathway (Figure 6C). In another control, Forskolin, a chemical activator of adenylate cyclase was added (Sapio et al. 2017). Both arginine-vasopressin (AVP), the V2R agonist, and forskolin led to a BRET decrease in V2R-expressing cells (Fig 6B and C).

\section{PfSR12 expression in HEK293 cell surface}

To verify the amount of PfSR12 expression on the cell membrane an ELISA was performed. In this experiment, the cells were fixed and incubated with anti-HA antibody without permeabilization, which allows measuring only proteins at the extracellular surface of the cells. As shown in Figure 7, a significant signal was observed in cells expressing the HA-PfSR12 above the background detected in cells transfected with the non-tagged PfSR12. However, the expression level detected was much smaller than that observed for the HA-tagged M3R indicating that the expression level of PfSR12 was relatively modest. In addition, to test whether the receptor under study could be cleaved 
by thrombin the cells were incubated with this protease prior to the assay, which would supposedly cause cleavage of the HA tag and decreased ELISA signal. No significant signal decrease could be observed for either PfSR12 or M3R, indicating that PfSR12 is neither cleaved nor internalized after activation by thrombin (Figure 7).

\section{PfSR12 promotes muscarinic receptor-dependent production of DAG and activation of PKC in a Gq/11-dependent manner}

To determine if the effect of PfSR12 was specific to thrombin and its effect on a different $\mathrm{Gq} / 11$-coupled receptor, the type 3-muscarinic receptor (M3R) was tested. HEK293SL cells were transfected with M3R which has a well characterized $G_{q / 11}$ activation mechanism. In addition, HEK293SL cells have endogenous M3R expression, which makes this receptor a good positive control for the experiments described.

PfSR12-transfected cells showed a significant increase in Carbamoyl Choline signal for DAG biosensor indicating a potentiation of the M3R responsiveness in these cells. The signal for DAG formation after carbamoyl choline treatment was high in M3R transfected cells (Figure $8 \mathrm{C}$ ), which corresponds to overexpression of muscarinic receptor, but was minimal for $\mathrm{D} 2 \mathrm{R}$ transfected cells (Figure $8 \mathrm{E}$ ), which most-likely corresponds to endogenous muscarinic receptor expression. PfSR12 transfected cells showed a high signal when compared to D2R transfected cells, but lower than M3R transfected cells (Figure 8A) indicating that PfSR12 promoted a muscarinic-induced DAG formationn. In all conditions, $\mathrm{G}_{\mathrm{q} / 11}$ inhibition by $\mathrm{YM}-254890$ blocked DAG formation (Figure $8 \mathrm{~B}, \mathrm{D}$, and $\mathrm{F}$ ).

Following the same reasoning, PKC biosensor was also tested. The BRET signal showing activation of PKC after carbamoyl choline treatment was also increased in PfSR12 transfected cells (Figure $8 \mathrm{G}$ ) when compared to D2R transfected cells (Figure $8 \mathrm{~K}$ ). M3R transfected cells showed the highest signal due to muscarinic receptor overexpression (Figure $8 \mathrm{I}$ ). Again, for all transfections, $\mathrm{G}_{\mathrm{q} / 11}$ inhibition blocked PKC activation (Figure $8 \mathrm{H}, \mathrm{J}$, and L).

\section{PfSR12 increases surface expression of mammalian GPCRs}

Our data suggested that PfSR12 was capable of activating $G_{q / 11}$ pathways for both thrombin and carbamoyl choline. It is unlikely that both agonists could bind and transduce a signal through PfSR12. Therefore, two hypotheses emerged from our data: first PfSR12 could act as a partner protein, interacting with other receptors to increase the transduced signal, and second, PfSR12 could act as a chaperone and increase the expression of other GPCRs. This can explain the increased signaling observed for 
thrombin (through endogenous PAR) and carbamoyl choline (through endogenous M3R).

To test if PfSR12 could increase the expression of these receptors, an ELISA was performed co-transfecting PfSR12 with M3R and D2R. V2R was used as a control to check if co-transfecting any two receptors could affect their respective expression. For this ELISA, only M3R and D2R were tagged and therefore all the signal observed came from these receptors. As illustrated in Figure 9, PfSR12 boosted the cell surface expression of M3R and D2R by $58 \%$ and $68 \%$ respectively, while V2R decreased the expression of both M3R and D2R by $62 \%$, as expected from classical co-transfection experiments most-likely due to a squelching of the transcription factors. This data supports the hypothesis of PfSR12 acting as a chaperone increasing the cell surface expression of other receptors.

\section{DISCUSSION}

Our results showed that HEK293 cells transfected with $P$. falciparum PfSR12 receptor can mobilize cytosolic calcium after stimulation with thrombin. Experiments using BRET-based biosensors have shown that the calcium increase after thrombin treatment could be explained by activation of the PLC-IP3 signaling pathway since we observed PKC activation and DAG formation.

The starting point of PLC-IP3 pathway is the activation of a GPCR coupled mainly to $G_{q / 11}$ family proteins. Indeed, using knockout cells for $G_{q / 11}$ family, no significant signal of PKC activation or DAG formation could be observed. When the same cells were supplemented with $G_{q}$, and $G_{11}$ it was possible to observe the signal restoration regarding PKC activation and DAG formation. The difference in intensity of the response for each $G$ protein can be explained either by a difference in the affinity of each $G$ protein for the receptor or by the expression level of each $G$ protein. The activation of $G_{q / 11}$ family is also pharmacologically supported by the inhibition of the response in the presence of YM-254890.

Although a canonical PKC could not be found in $P$. falciparum genome, there is an active PLC that participates in cell signaling processes, as well as orphan kinases that could supply the PKC deficiency acting in a similar way (Alves et al. 2011; Garcia et al. 2017; Moraes et al. 2017). Moreover, the parasite expresses a functional receptor for Kinase C (PfRACK) with conserved domains for PKC anchoring, which supports the possibility of another kinase playing the role of PKC (Madeira et al. 2008; Sartorello et al. 2009). The PfRACK is essential for $P$. falciparum development since the inducible knockdown impairs the asexual lifecycle (Blomqvist et al. 2017). 
In addition, the machinery for signal transduction through Gq-PLC-IP3 pathway is active inside the host cell and plays an important role in cytoskeleton remodeling (Franco and Low 2010; Muravyov et al. 2012). We cannot rule out that the parasite may have access to this signal transduction machinery during infection. Therefore, the expression of PfSR12 by $P$. falciparum could serve as an alternative mechanism of activation of the erythrocyte cytoskeleton remodeling pathway, which would facilitate processes such as parasite egress and/or lysis of the host cell.

The effect of PfSR12 on the Gq pathway responsiveness was not restricted to thrombin. Indeed, the expression of PfSR12 significantly potentiated the $\mathrm{Gq}$ response to carbamoyl choline stimulation. Given that it is unlikely that PfSR12 could be directly activated by both thrombin and carbamoyl choline; two unrelated ligands. The responses likely result from a potentiation of the endogenously expressed PAR and M3 muscarinc receptor in HEK-293 cells (Atwood et al. 2011; Hussmann et al. 2011). Two hypotheses emerged from our data: first PfSR12 could act as a partner protein, interacting with other receptors to increase the transduced signal, and second, PfSR12 could act as a chaperone and increase the expression of other GPCRs. It is known that the homo/hetero oligomerization of GPCRs happen and can alter the subcellular localization of receptors (Benke et al. 1999; Gama et al. 2001; Hague et al. 2004b, 2004a; Salahpour et al. 2004; Chang et al. 2007).

To test the hypothesis of change in expression after PfSR12 transfection, an ELISA assay was performed by co-expressing PfSR12 and other mammalian receptors. The results showed that PfSR12 can increase the expression of other receptors in HEK293 cells plasma membrane. Cell surface expression of both the M3 and D2 receptors were found to be increased by $\sim 60 \%$ increase upon expression of PfSR12 whereas expression of another GPCR, the V2R, decreasd the expression of the M3 and D2 confirming that the positive effect of PfSR12 on other GPCR expression is selective and not a non-specific effect of cotransfecting any other membrane protein.

Taken together, these result indicate that the increase of the observed $\mathrm{Gq}$ signaling is not due to the direct action thrombin or carbamoyl choline on PfSR12, but rather to an increase of plasma membrane PAR and $M 3$ receptors endogenously expressed in HEK293 cells and capable of triggering signaling. In fact, PAR and M3R have the same signaling profile observed in this work: PAR1 and PAR4, the main thrombin receptors that are endogenously expressed in HEK293 cells (Atwood et al. 2011), couple with the $G_{q / 11}$ family but not with $G_{s}$ (Heuberger and Schuepbach 2019). Other evidence suggesting that signaling is not due to interaction between thrombin and PfSR12 is the absence of ELISA signal loss following treatment with thrombin, which is indicative of two hypotheses: (1) the receptor is not activated because there is no 
internalization and (2) is not cleaved as this would lead to loss of epitope sign. The M3R, known to be expressed in HEK293 cells is also known to activate Gq but not Gs (Kruse et al. 2012).

Our results indicate that PfSR12 may act as an accessory protein facilitating the plasma membrane trafficking of other $G$ proteins. The gamma-aminobutyric acid receptor $\mathrm{GABA}_{\mathrm{B} 2}$ subtype exemplifies this role well. The GABA $\mathrm{B}_{\mathrm{B}}$ receptor is a GPCR expressed in the central nervous system, where it controls the opening of potassium channels in the membranes of neurons, reducing the release of neurotransmitters. However, the $\mathrm{GABA}_{B}$ receptor is only active if it is in its dimeric form consisting of two subtypes: $\mathrm{GABA}_{\mathrm{B} 1}$ and $\mathrm{GABA} \mathrm{B}_{2}$. While the $\mathrm{B} 1$ subunit is responsible for binding the agonist, the $\mathrm{b} 2$ subunit does not have a specific ligand binding site but is essential for the functional expression of the B1 subunit at the cell surface (White et al. 1998; Villemure et al. 2005; Pin and Bettler 2016).

The traffic of $P$. falciparum proteins is complex, as it involves transporting through several sets of membranes that are not present in the eukaryotic cells of non-parasitic organisms, such as the parasitophorous vacuole membrane. To overcome this barrier, hundreds of proteins that have their final destination in the erythrocyte cytosol or membrane have a Plasmodium export element motif (PEXEL) which allows the transit of proteins from inside the parasite to the erythrocyte cytosol through the action of Plasmodium translocon of exported proteins (PTEX) (Boddey et al. 2009, 2016; Elsworth et al. 2014). Several proteins are PEXEL-negative and are also transported to the erythrocyte via PTEX by a still unknown mechanism (Heiber et al. 2013). PfSR12 is one of the PEXEL-negative proteins, and evidence that this protein is a chaperone that aids in the transport of other receptors in mammals may indicate that PfSR12 would be able to assist in the transport of PEXEL-negative proteins during the development of the parasite.

The present data uses heterologous transfection, BRET/luminescence-based biosensors and knock-out cells as tools to contribute to our understanding of the potential role of malarial proteins in signal transduction pathways at work in host-parasite interaction. PfSR12 is a Plasmodium GPCR-like protein that displays a classical behavior of GPCR chaperone function and promote activation of $\mathrm{G}_{\mathrm{q} / 11}$ signaling pathway in HEK293 cells.

\section{Acknowledgment}

This work was supported by the Fundação de Amparo à Pesquisa do Estado de São Paulo (FAPESP) 2017/08684-7 to CG, 2014/14347-5 and 2017/16307-9 to PHSP 
as well as by a Foundation grant of the Canadian Institute for Health Research (FDN148431) to MB. MB also holds the Canada Research Chair in in Signal Transduction and Molecular Pharmacology.

\section{References}

Adams MN, Ramachandran R, Yau MK, Suen JY, Fairlie DP, Hollenberg MD, et al. Structure, function and pathophysiology of protease activated receptors. Pharmacol Ther. 2011;130(3):248-82.

Alves E, Bartlett PJ, Garcia CRS, Thomas AP. Melatonin and IP3-induced Ca2+ release from intracellular stores in the malaria parasite Plasmodium falciparum within infected red blood cells. J Biol Chem [Internet]. 2011;286(7):5905-12. Available from:

http://www.pubmedcentral.nih.gov/articlerender.fcgi?artid=3037703\&tool=pmcentr ez\&rendertype=abstract

Amato R, Pearson RD, Almagro-Garcia J, Amaratunga C, Lim P, Suon S, et al. Origins of the current outbreak of multidrug-resistant malaria in southeast Asia: $A$ retrospective genetic study. The Lancet Infectious Diseases. 2018;

Atwood BK, Lopez J, Wager-Miller J, Mackie K, Straiker A. Expression of G proteincoupled receptors and related proteins in HEK293, AtT20, BV2, and N18 cell lines as revealed by microarray analysis. BMC Genomics. 2011;

Avril M, Benjamin M, Dols MM, Smith JD. Interplay of Plasmodium falciparum and thrombin in brain endothelial barrier disruption. Sci Rep. 2019;

Benke D, Honer M, Michel C, Bettler B, Mohler H. Y-Aminobutyric acid type B receptor splice variant proteins GBR1a and GBR1b are both associated with GBR2 in situ and display differential regional and subcellular distribution. J Biol Chem. 1999;

Blomqvist K, DiPetrillo C, Streva VA, Pine S, Dvorin JD. Receptor for Activated CKinase 1 (PfRACK1) is required for Plasmodium falciparum intra-erythrocytic proliferation. Mol Biochem Parasitol. 2017;

Boddey JA, Moritz RL, Simpson RJ, Cowman AF. Role of the Plasmodium export element in trafficking parasite proteins to the infected erythrocyte. Traffic. 2009;

Boddey JA, O'Neill MT, Lopaticki S, Carvalho TG, Hodder AN, Nebl T, et al. Export of malaria proteins requires co-translational processing of the PEXEL motif independent of phosphatidylinositol-3-phosphate binding. Nat Commun. 2016;

Breton B, Sauvageau É, Zhou J, Bonin H, Le Gouill C, Bouvier M. Multiplexing of 
multicolor bioluminescence resonance energy transfer. Biophys J. 2010;

Chang W, Tu C, Cheng Z, Rodriguez L, Chen TH, Gassmann M, et al. Complex formation with the type $\mathrm{B} Y$-aminobutyric acid receptor affects the expression and signal transduction of the extracellular calcium-sensing receptor: Studies with HEK-293 cells and neurons. J Biol Chem. 2007;

Elsworth B, Matthews K, Nie CQ, Kalanon M, Charnaud SC, Sanders PR, et al. PTEX is an essential nexus for protein export in malaria parasites. Nature [Internet]. 2014;511(7511):587-91. Available from: http://www.nature.com/doifinder/10.1038/nature13555

Francischetti IMB, Seydel KB, Monteiro RQ. Blood coagulation, inflammation, and malaria. Microcirculation [Internet]. 2008;15(2):81-107. Available from: http://www.ncbi.nlm.nih.gov/pubmed/18260002\%5Cnhttp://www.pubmedcentral.ni h.gov/articlerender.fcgi?artid=PMC2892216

Francischetti IMB, Seydel KB, Monteiro RQ, Whitten RO, Erexson CR, Noronha ALL, et al. Plasmodium falciparum-infected erythrocytes induce Tissue Factor expression in endothelial cells and support the assembly of multimolecular coagulation complexes. J Thromb Haemost [Internet]. 2007 Jan 26;5(1):155-65. Available from: http://www.ncbi.nlm.nih.gov/pmc/articles/PMC2892312/

Franco T, Low PS. Erythrocyte adducin: A structural regulator of the red blood cell membrane. Transfus Clin Biol. 2010;

Gama L, Wilt SG, Breitwieser GE. Heterodimerization of Calcium Sensing Receptors with Metabotropic Glutamate Receptors in Neurons. J Biol Chem. 2001;

Garcia CRS, Alves E, Pereira PHS, Bartlett PJ, Thomas AP, Mikoshiba K, et al. InsP3 Signaling in Apicomplexan Parasites. Curr Top Med Chem [Internet]. 2017;17(19). Available from: http://www.eurekaselect.com/149618/article

Gealageas R, Malikova NP, Picaud S, Borgdorff AJ, Burakova LP, Brûlet P, et al. Bioluminescent properties of obelin and aequorin with novel coelenterazine analogues. Anal Bioanal Chem. 2014;

Hague C, Uberti MA, Chen Z, Bush CF, Jones S V., Ressler KJ, et al. Olfactory receptor surface expression is driven by association with the 2-adrenergic receptor. Proc Natl Acad Sci. 2004a;

Hague C, Uberti MA, Chen Z, Hall RA, Minneman KP. Cell Surface Expression of a1DAdrenergic Receptors Is Controlled by Heterodimerization with a1D-Adrenergic Receptors. J Biol Chem. 2004b;. 
Heiber A, Kruse F, Pick C, Grüring C, Flemming S, Oberli A, et al. Identification of New PNEPs Indicates a Substantial Non-PEXEL Exportome and Underpins Common Features in Plasmodium falciparum Protein Export. PLoS Pathog. 2013;

Heuberger DM, Schuepbach RA. Protease-activated receptors (PARs): Mechanisms of action and potential therapeutic modulators in PAR-driven inflammatory diseases. Thrombosis Journal. 2019.

Houle S, Hollenberg MD. Proteinase-activated receptors. In: xPharm: The Comprehensive Pharmacology Reference. 2011. p. 1-12.

Hussmann GP, Yasuda RP, Xiao Y, Wolfe BB, Kellar KJ. Endogenously expressed muscarinic receptors in HEK293 cells augment up-regulation of stably expressed a4ß2 nicotinic receptors. J Biol Chem. 2011;

Illarionov BA, Frank LA, Illarionova VA, Bondar VS, Vysotski ES, Blinks JR.

Recombinant obelin: Cloning and expression of cDNA, purification, and characterization as a calcium indicator. Methods in Enzymology. 2000.

Kenakin T. New concepts in pharmacological efficacy at 7TM receptors: IUPHAR Review 2. British Journal of Pharmacology. 2013.

Kruse AC, Hu J, Pan AC, Arlow DH, Rosenbaum DM, Rosemond E, et al. Structure and dynamics of the M3 muscarinic acetylcholine receptor. Nature. 2012;

Lander ES, Linton LM, Birren B, Nusbaum C, Zody MC, Baldwin J, et al. Initial sequencing and analysis of the human genome. Nature. 2001;

Madeira L, Galante PAF, Budu A, Azevedo MF, Malnic B, Garcia CRS. Genome-wide detection of serpentine receptor-like proteins in malaria parasites. PLoS One. 2008;3(3).

Ménard D, Clain J, Ariey F. Multidrug-resistant Plasmodium falciparum malaria in the Greater Mekong subregion. The Lancet Infectious Diseases. 2018;

Moraes MS, Budu A, Singh MK, Borges-Pereira L, Levano-Garcia J, Currà C, et al. Plasmodium falciparum GPCR-like receptor SR25 mediates extracellular K+ sensing coupled to Ca2+ signaling and stress survival. Sci Rep [Internet]. 2017;7(1):9545. Available from: http://www.nature.com/articles/s41598-01709959-8

Muravyov A V., Maimistova AA, Tikhomirova IA, Bulaeva S V., Mikhailov P V., Muravyov AA. Role of protein kinases of human red cell membrane in deformability and aggregation changes. Hum Physiol. 2012;

Namkung Y, LeGouill C, Kumar S, Cao Y, Teixeira LB, Lukasheva V, et al. Functional 
selectivity profiling of the angiotensin II type 1 receptor using pathway-wide BRET signaling sensors. Sci Signal. 2018;

Pin JP, Bettler B. Organization and functions of mGlu and GABA B receptor complexes. Nature. 2016.

Riedl J, Mordmüller B, Koder S, Pabinger I, Kremsner PG, Hoffman SL, et al. Alterations of blood coagulation in controlled human malaria infection. Malar $\mathrm{J}$. 2016;

Rosenbaum DM, Rasmussen SGF, Kobilka BK. The structure and function of Gprotein-coupled receptors. Nature. 2009.

Salahpour A, Angers S, Mercier JF, Lagacé M, Marullo S, Bouvier M.

Homodimerization of the $\beta 2$-adrenergic receptor as a prerequisite for cell surface targeting. J Biol Chem. 2004;

Sapio L, Gallo M, Illiano M, Chiosi E, Naviglio D, Spina A, et al. The Natural cAMP Elevating Compound Forskolin in Cancer Therapy: Is It Time? J Cell Physiol. 2017;

Sartorello R, Amaya MJ, Nathanson MH, Garcia CRS. The plasmodium receptor for activated $\mathrm{C}$ kinase protein inhibits $\mathrm{Ca} 2+$ signaling in mammalian cells. Biochem Biophys Res Commun. 2009;389(4):586-92.

Takasaki J, Saito T, Taniguchi M, Kawasaki T, Moritani Y, Hayashi K, et al. A novel Gaq/11-selective inhibitor. J Biol Chem. 2004;

Tsukada S, Iwai M, Nishiu J, Itoh M, Tomoike H, Horiuchi M, et al. Inhibition of experimental intimal thickening in mice lacking a novel G-protein-coupled receptor. Circulation. 2003;

Villemure JF, Adam L, Bevan NJ, Gearing K, Chénier S, Bouvier M. Subcellular distribution of GABAB receptor homo- and hetero-dimers. Biochem J. 2005;

White JH, Wise A, Main MJ, Green A, Fraser NJ, Disney GH, et al. Heterodimerization is required for the formation of a functional $\operatorname{GABA}(B)$ receptor. Nature. 1998;

World Health Organization. World Malaria Report 2016. World Health Organization. 2016. 

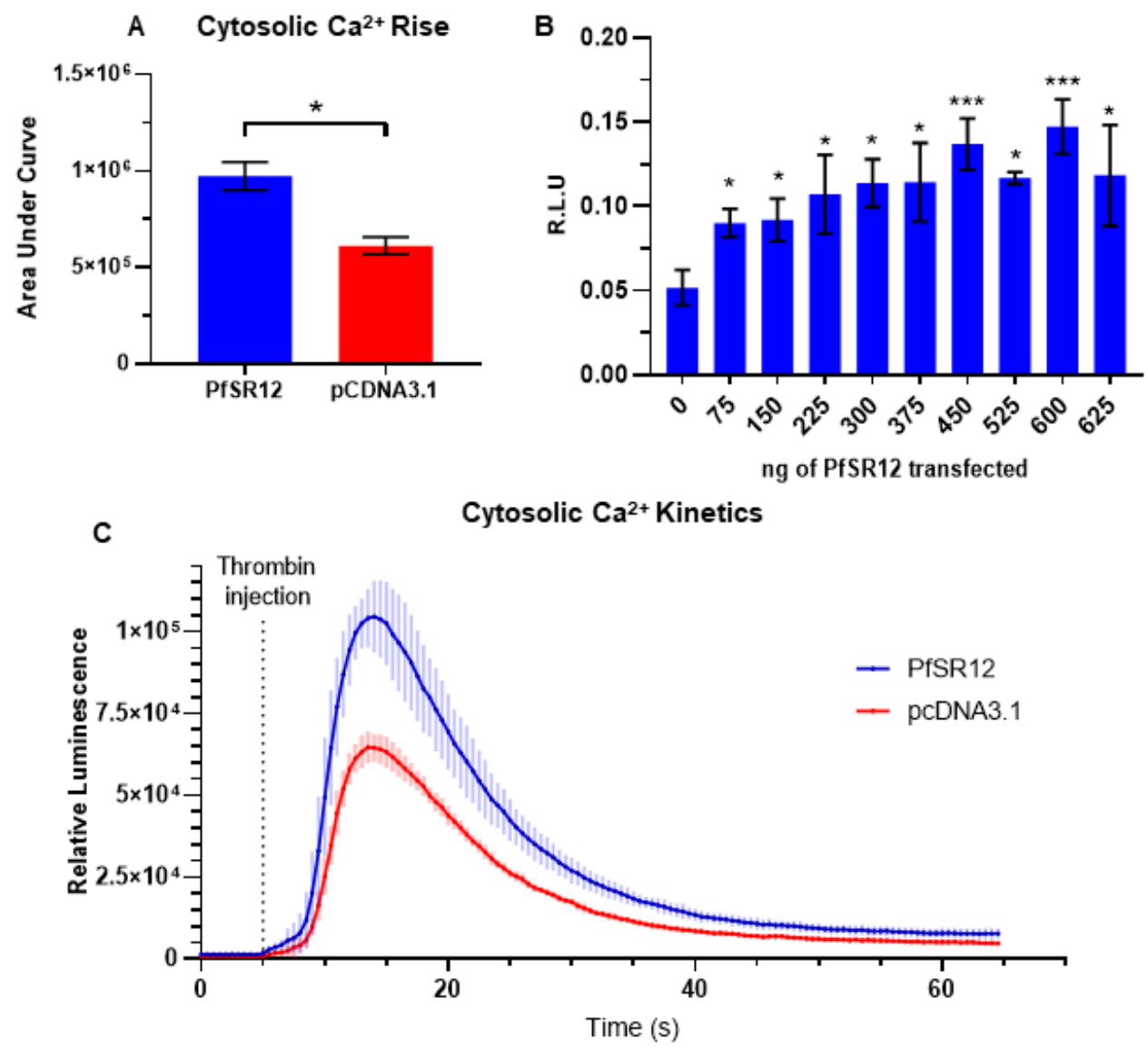

Figure 1. 

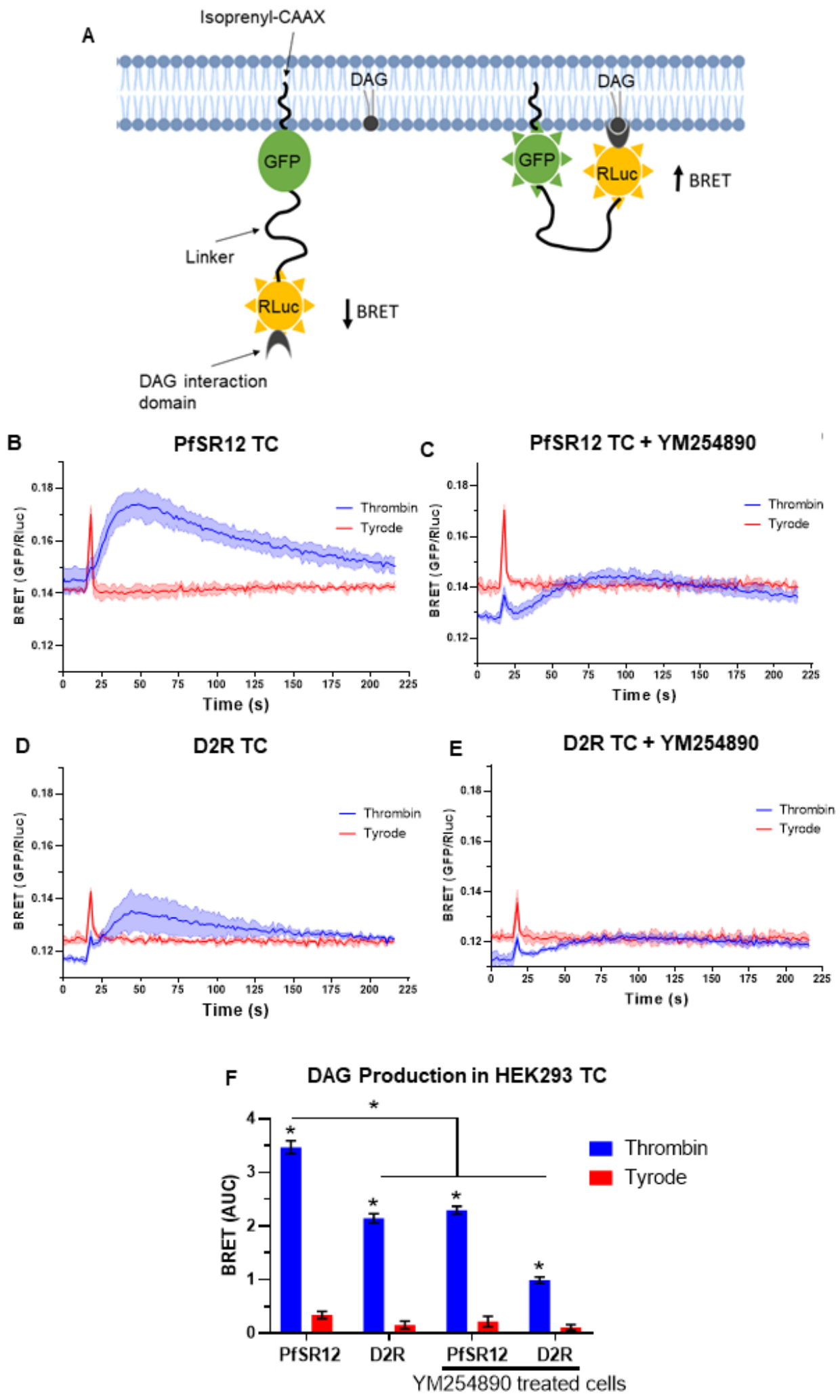

Figure 2. 
A

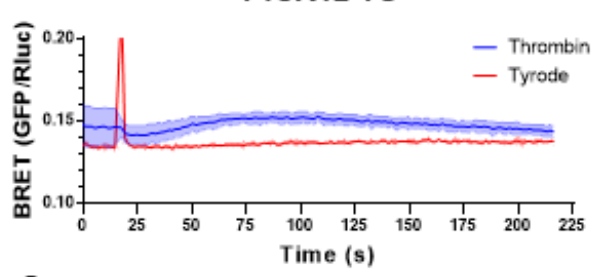

C

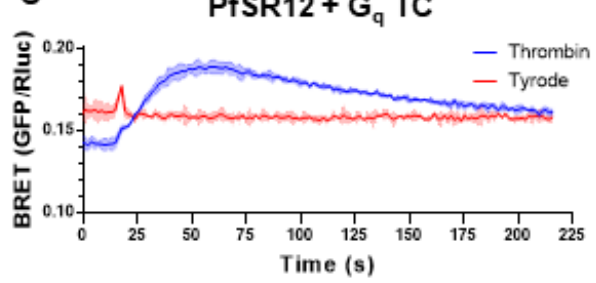

E

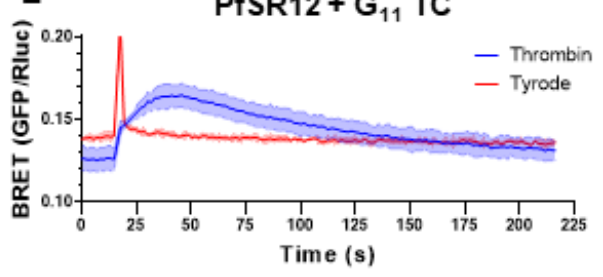

B

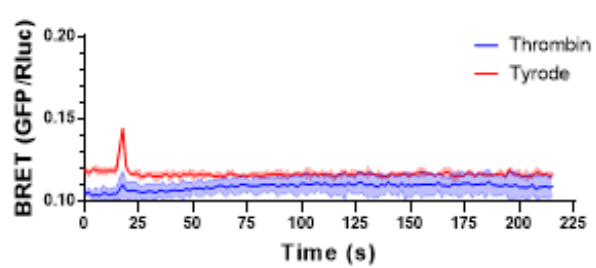

D
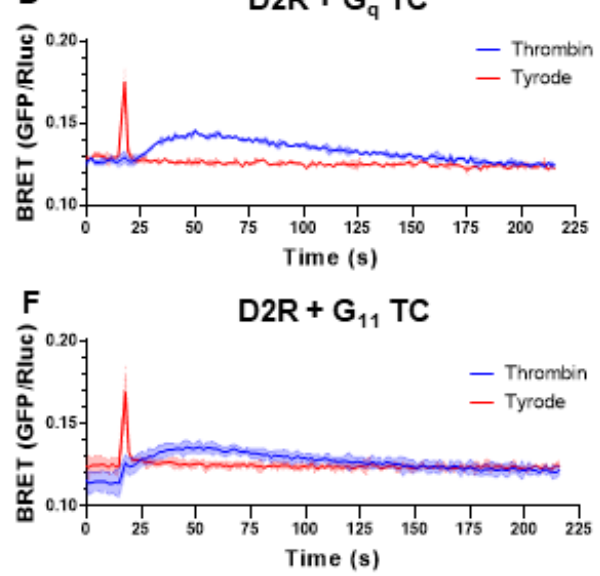

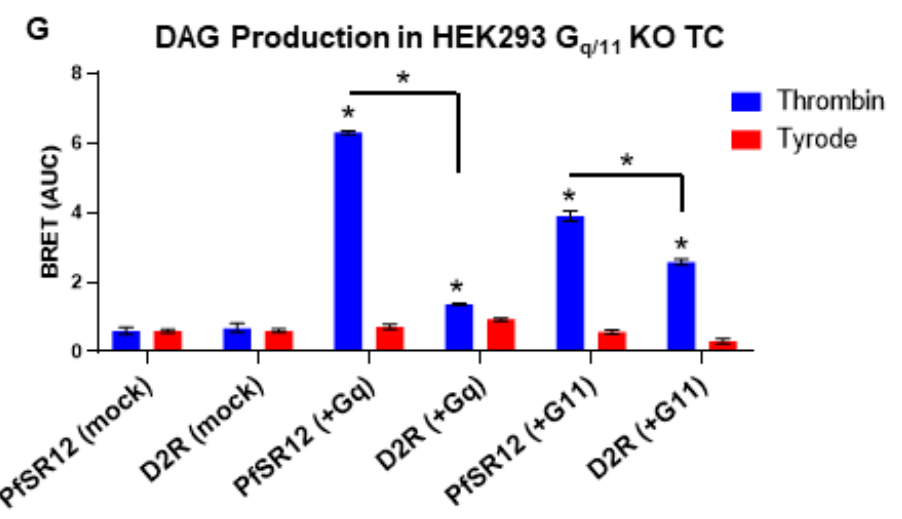

Figure 3. 
A

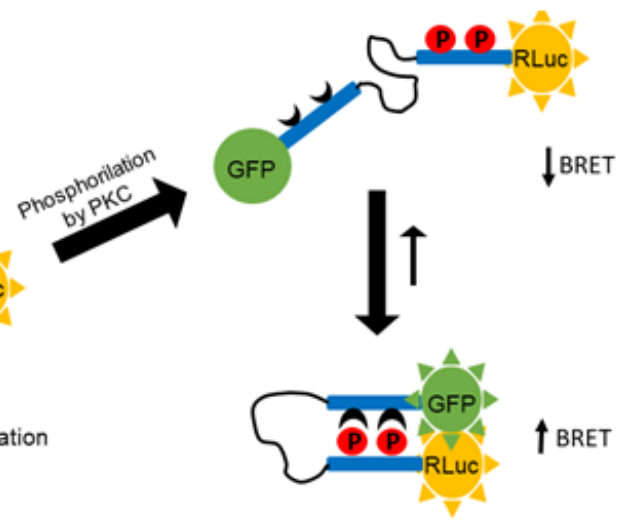

B

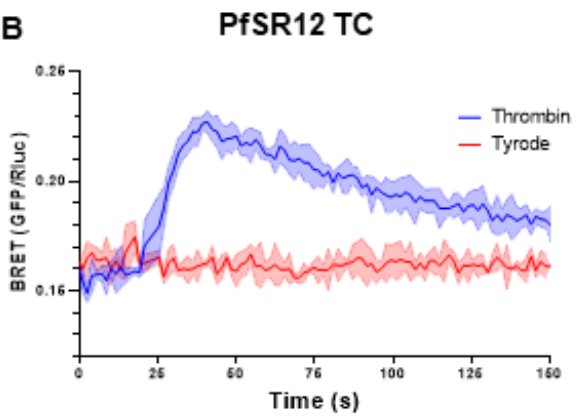

D

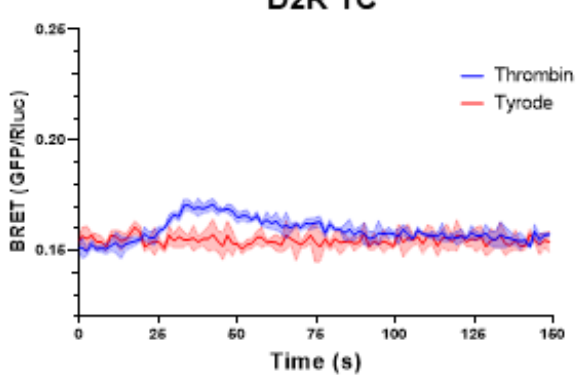

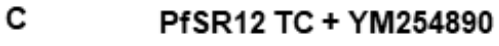

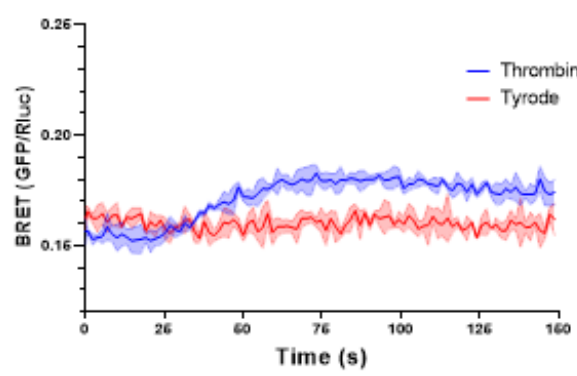

E

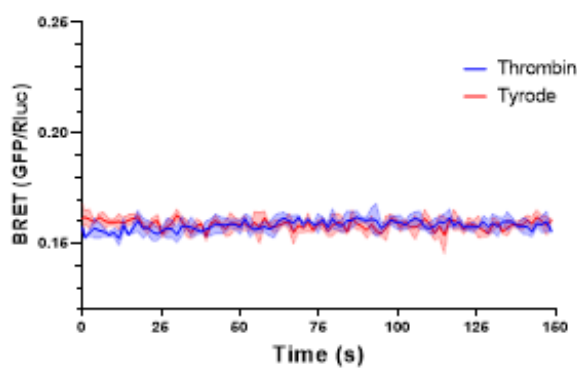

F PKC Activation in HEK293 TC

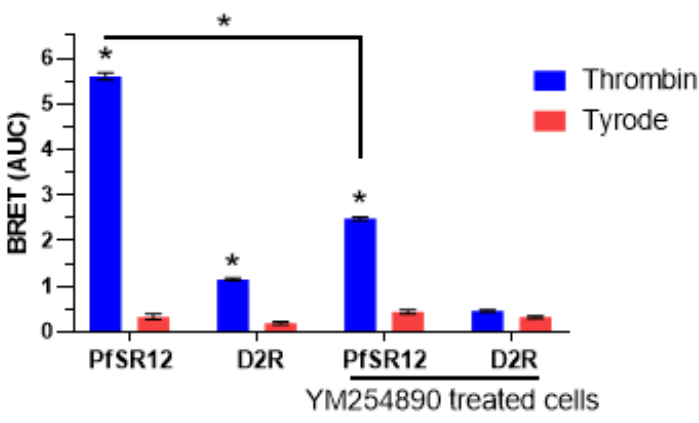

Figure 4. 

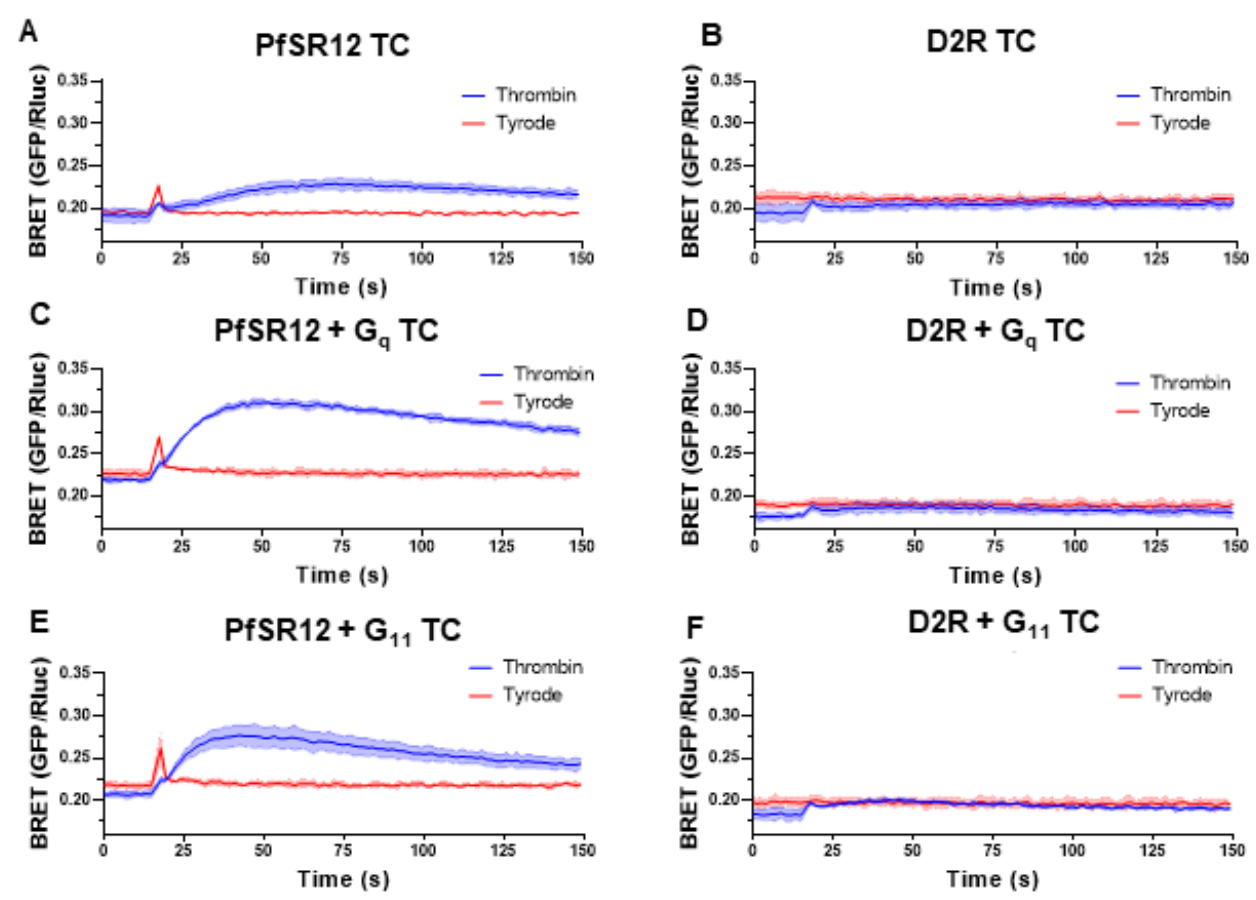

G PKC Activation in HEK293 $\mathrm{G}_{\mathrm{q} / 11} \mathrm{KO}$ TC

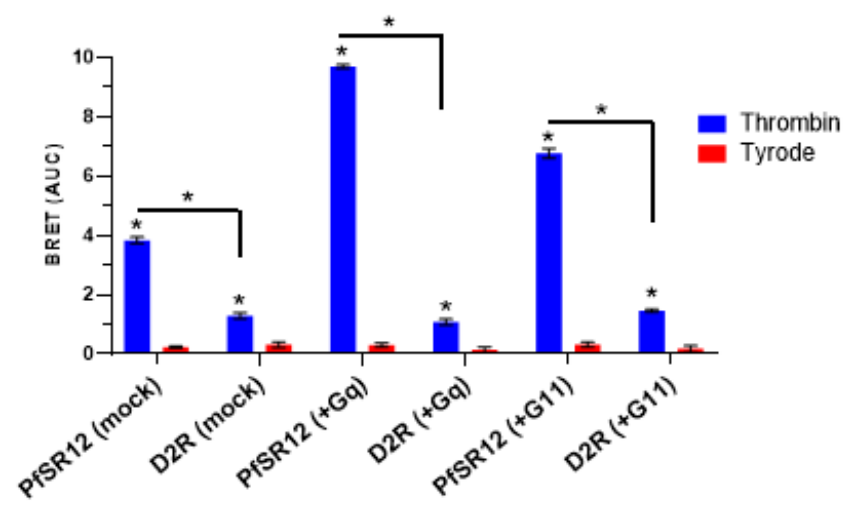

Figure 5 
A

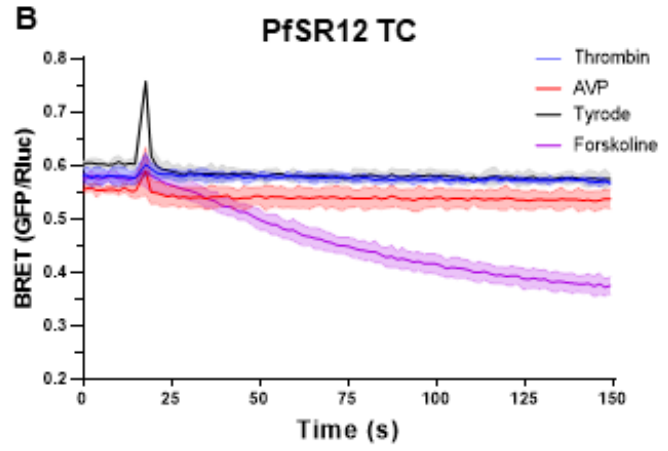

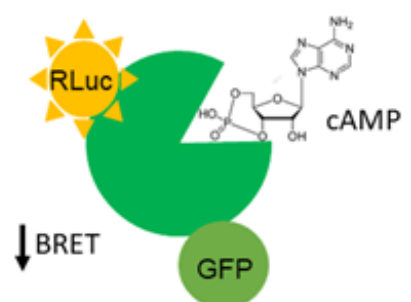

C

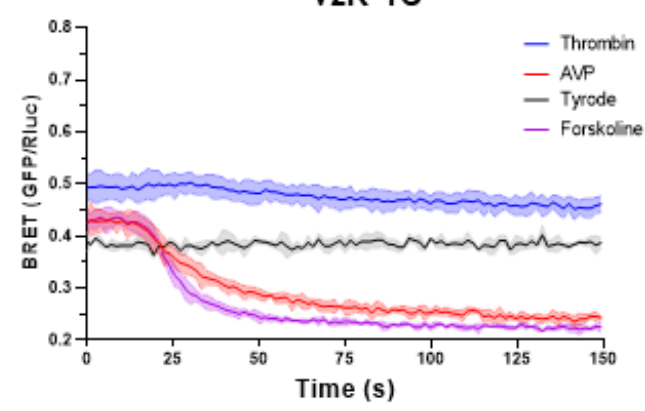

Figure 6. 


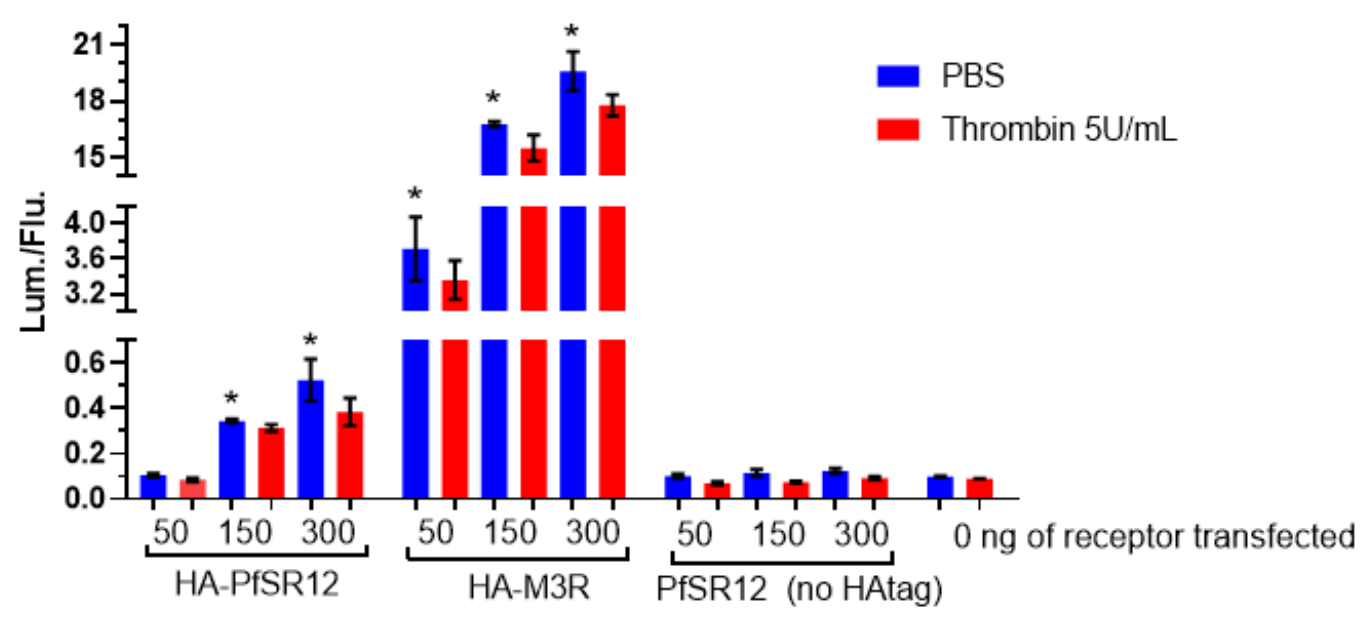

Figure 7. 

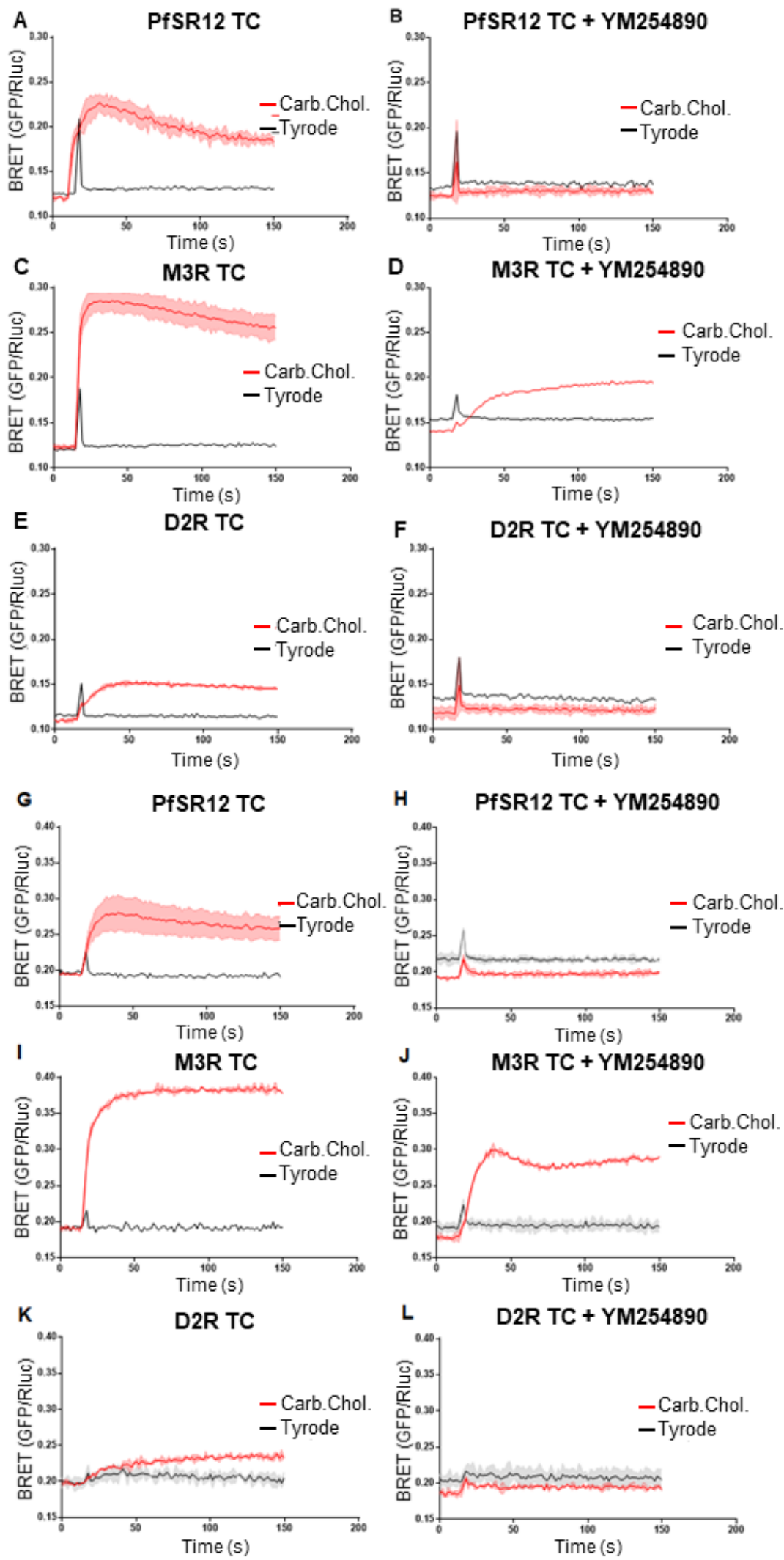

Figure 8. 


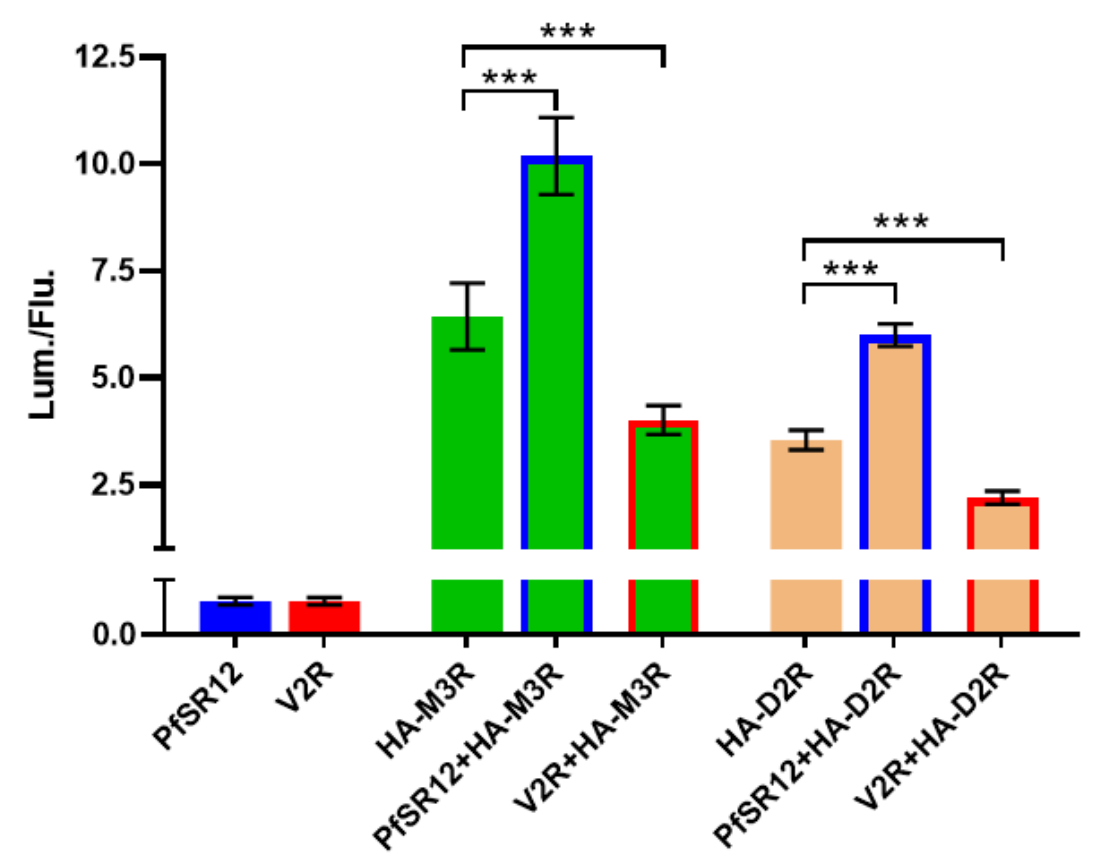

Figure 9. 


\section{FIGURES LEGENDS}

Figure 1. Cytosolic $\mathrm{Ca}^{2+}$ response after dose-dependent thrombin treatment in HEK293SL cells transfected with PfSR12. HEK293SL cells were co-transfected with Obelin/Ca ${ }^{2+}$ biosensor and PfSR12. $2 \mathrm{U} / \mathrm{mL}$ thrombin induces $\mathrm{Ca}^{2+}$ rise in PfSR12 transfected cells when compared to mock cells $(A)$. This $\mathrm{Ca}^{2+}$ rise is dependent of the amount of PfSR12 transfected (B). (C) shows a typical kinetics experiment. * Statistically significant by Student's $T$ test for two means (A). For figure $B$, statistically significant by two-way ANOVA with post-test $\mathrm{T}$ and $\mathrm{P}<0.05\left(^{*}\right)$ or $\mathrm{P}<0.001\left(^{* * *}\right)$.

Figure 2. DAG production measurement PfSR12 and D2R transfected cells (PfSR12 TC and D2R TC) followed by thrombin treatment. (A) DAG biosensor. (B) HEK293 SL cells were co-transfected with PfSR12 and DAG biosensor and then treated with thrombin $(2 \mathrm{U} / \mathrm{mL})$ or buffer (Tyrode). (D) Negative control was done transfecting cells with D2R and treated with Dopamine or buffer (Tyrode). (C) and (E) Transfected cells with PfSR12 or DAG biosensor were treated with protein $G_{q / 11}$ inhibitor (YM-254890) followed by Thrombin or Dopamine addition, respectively. Luminescence and fluorescence were measured simultaneously to calculate BRET values in real time. $(F)$ Bar graphs showing mean values of signal using area under curve of three experiments. * statistically significant by two-way ANOVA with post-test T.

Figure 3. DAG production measurement in $\mathrm{G}_{\mathrm{q} / 11}$ Knockout cells expressing PfSR12 and D2R (PfSR12 TC and D2R TC) followed by thrombin treatment with $G_{q / 11}$ rescue. (A) HEK293 SL G $\mathrm{q}_{/ 11} \mathrm{KO}$ cells were co-transfected with PfSR12 + DAG biosensor and treated with thrombin $(2 \mathrm{U} / \mathrm{mL})$ or buffer (Tyrode). $\mathrm{G}_{\mathrm{q} / 11}$ rescue experiment was performed transfecting KO cells with PfSR12 + DAG biosensor $+G_{\alpha}\left(G_{q}(C) ; G_{11}\right.$ (E). Negative control was done transfecting cells with D2R + DAG biosensor and treated with thrombin $\left(2 \mathrm{U} / \mathrm{mL}\right.$ ) or buffer (Tyrode) $(B) . G_{q / 11}$ rescue negative control experiment was performed transfecting KO cells with D2R + DAG biosensor + Ga $\left(G_{q}(D) ; G_{11}(F)\right.$. Luminescence and fluorescence were measured simultaneously to calculate BRET values in real time. (G) Bar graphs showing mean values of signal using area under curve of three experiments. ${ }^{*}$ statistically significant by two-way ANOVA with post-test T.

Figure 4. PKC biosensor BRET measurement in PfSR12 and D2R transfected cells (PfSR12 TC and D2R TC) followed by thrombin treatment. (A) PKC biosensor. (B) HEK293 SL cells were co-transfected with PfSR12 and PKC biosensor and treated with thrombin $(2 \mathrm{U} / \mathrm{mL})$ or buffer (Tyrode). (D) Negative control was done transfecting cells 
with D2R and treated with thrombin $(2 \mathrm{U} / \mathrm{mL})$ or buffer (Tyrode). PfSR12 (C) or D2R (E) transfected cells were treated with $\mathrm{G}_{\mathrm{q} / 11}$ inhibitor (YM-254890) followed by thrombin treatment. Luminescence and fluorescence were measured simultaneously to calculate BRET values in real time. (F) Bar graphs showing mean values of signal using area under curve of three experiments. * statistically significant by two-way ANOVA with posttest $\mathrm{T}$.

Figure 5. PKC biosensor BRET measurement in $\mathrm{G}_{\mathrm{q} / 11}$ Knockout cells expressing PfSR12 and D2R (PfSR12 TC and D2R TC) followed by thrombin treatment with $\mathbf{G}_{q / 11}$ rescue. (A) HEK293 SL $G_{q / 11}$ KO cells were co-transfected with PfSR12 + PKC biosensor and treated with thrombin $\left(2 \mathrm{U} / \mathrm{mL}\right.$ ) or buffer (Tyrode). $\mathrm{G}_{\mathrm{q} / 11}$ rescue experiment was performed transfecting KO cells with PfSR12 + PKC biosensor + Ga (Gq (C); G11 $(E))$. Negative control was done transfecting cells with $\mathrm{D} 2 \mathrm{R}+\mathrm{PKC}$ biosensor and treated with thrombin $\left(2 \mathrm{U} / \mathrm{mL}\right.$ ) or buffer (Tyrode) $(B) . G_{q / 11}$ rescue negative control experiment was performed transfecting KO cells with D2R + PKC biosensor + Ga (Gq (D); G11 (F). Luminescence and fluorescence were measured simultaneously to calculate BRET values in real time. (G) Bar graphs showing mean values of signal using area under curve of three experiments. * statistically significant by two-way ANOVA with post-test T.

Figure 6. EPAC biosensor BRET measurement in cells expressing PfSR12 followed by thrombin treatment. (A) EPAC biosensor. (B) HEK293 SL cells were cotransfected with PfSR12 and EPAC biosensor, and treated with thrombin $(2 \mathrm{U} / \mathrm{mL})$, vasopressin, forskolin or buffer (Tyrode). (C) Positive control was done transfecting cells with $\mathrm{V} 2 \mathrm{R}$ and treating with thrombin $(2 \mathrm{U} / \mathrm{mL})$ arginine-vasopressin (AVP), forskolin or buffer (Tyrode). Luminescence and fluorescence were measured simultaneously to calculate BRET values in real time.

Figure 7. Surface ELISA of PfSR12 and M3R transfected cells with and without thrombin treatments. HEK293SL cells were transfected with different concentrations of HA-tagged PfSR12, HA-tagged M3R or untagged PfSR12 and expression was quantified by ELISA using anti-HA antibody. Thrombin was added to a final concentration of $5 \mathrm{U} / \mathrm{mL}$ for 5 minutes before fixing the cells to access if receptors could be cleaved due to protease activity and lose the $\mathrm{N}$-terminal HA-tag. PfSR12 expression was about 40 lower than M3R transfected cells. * statistically significant by two-way ANOVA with post-test T when compared to unstrasfected cells without thrombin incubation. No significant difference was observed after 5 minutes of incubation with $5 \mathrm{U} / \mathrm{mL}$ thrombin. 
Figure 8. DAG formation and PKC activation measurements in cells expressing PfSR12, M3R and D2R followed by carbamoyl choline treatment. For DAG biosensor HEK293SL cells were co-transfected with receptor (PfSR12 (A-B), M3R (C-D) or D2R $(E-F))$ and DAG biosensor and then treated with carbamoyl choline $(10 \mu \mathrm{M})$ or buffer (Tyrode). Transfected cells were treated with $\mathrm{G}_{\mathrm{q} / 11}$ inhibitor (YM-254890) followed by carbamoyl choline addition ( $B, D$ and $F$ ). Luminescence and fluorescence were measured simultaneously to calculate BRET values in real time. For PKC biosensor, HEK293SL cells were co-transfected with receptor (PfSR12 (G-H), M3R (I-J) or D2R (KL)) and PKC biosensor and then treated with carbamoyl choline $(10 \mu \mathrm{M})$ or buffer (Tyrode). Transfected cells were treated with $\mathrm{G}_{\mathrm{q} / 11}$ inhibitor (YM-254890) followed by carbamoyl choline addition $(\mathrm{H}, \mathrm{J}$ and $\mathrm{L})$. Luminescence and fluorescence were measured simultaneously to calculate BRET values in real time.

Figure 9. Surface ELISA with Co-transfected cells. HEK293 Cells were transfected using 200ng of each receptor and detected on the membrane surface by ELISA using anti-HA antibody. PfSR12 and V2R untagged versions were used, so no signal was expected for these receptors. M3R and D2R HA-tagged versions were used, which showed a positive luminescence increase. ${ }^{*}$ statistically significant by two-way ANOVA with post-test $\mathrm{T}$. 